\title{
An Improved Algebraic Method for Finding the Jump Height of Iced Transmission Lines
}

\author{
Rashmi S. \\ Vidyavardhaka College of Engineering and JSS \\ Research Foundation, \\ Gokulum $3^{\text {rd }}$ Stage, \\ Mysuru, Karnataka, India
}

\author{
Shankaraiah \\ Sri Jayachamarajendra College of Engineeing \\ Mysuru, Karnataka, India
}

\begin{abstract}
An increase in the weight of the conductor in an $\mathrm{AC}$ transmission line due to external loading like ice, wind etc., increases the physical sag which in turn displaces the jump height and in a multi span conductor system with unequal loading leads to arching as well. There are situations where flashover may also take place when phase to phase distance becomes small or phase to tower distance becomes small because of icing on transmission lines. Hence monitoring the changes in conductor span between tower tie up's needs to have a careful attention for its variations. This paper proposes an improved calculation using algebraic method to calculate the tension created in the line with its immediate sag effect considering ice and wind loading applied for both levelled and unlevelled spans. We see that the proposed method is able to arrive at horizontal tension within 6 iterations as compared with Newton Raphson method which takes 7 iterations and the error on application is only $0.0119 \%$ for horizontal tension on which the sag is dependent on.
\end{abstract}

\section{General Terms}

Transmission line, Horizontal Tension, Iteration, Error.

\section{Keywords}

Jump Height, Icing, Physical sag, Multi span, Algebraic method, Newton Raphson method

\section{INTRODUCTION}

The natural circumstances happening in cold regions like heavy blow of wind and high thick ice getting deposited on transmission line conductors has various hazardous affects at the power utility end. The accumulation of ice may not be uniform over the conductor length and over a period of time leads to sagging of line conductors. For pole towers at equal height it is always taken that the lowest point of conductor sag is at the middle of the span and for unlevel span systems the lowest point of sag will be nearing the pole tower at lesser height. Stability to the construction of lines is also important. Many short circuits have taken place because of ice getting warmer with temperature change, however the effect of temperature is very small and the type of insulator used at the pole tower level also has its contribution according to the authors of [1].The authors of [2] have dealt with a icing model behavior considering the heat generated for different current flow in the line. The rate at which ice melts is plotted based on certain assumptions and we see that the conductor heat over ice melting has only marginal effect. The authors of paper [3] use a non-standard co-ordinate system for conductor curve i.e., all distances are measured from left hand side support of the span as opposed to the conventional methods in which the distances are measured from the conductor low point. The authors have solved the catenary equation using methods like derivative of the conductor curve, finding biggest levelled span within inclined one and representing the equation of parabola in its vertex form. These techniques are applied for both levelled and unlevelled spans, however in all the calculations the relation between sag and conductor weight is not taken into consideration. The authors of [4] have done the line sag calculations using affine arithmetic method and have compared the results with Monte Carlo method and internal arithmetic methods. In spite of rigorous mathematical modelling used, there is no significant improvement in the results and they have not considered the case of unlevelled span. The authors of [5] have investigated the dynamic response of multi span transmission lines with different structural parameters using a numerical modelling method of ice load and ice shedding. The authors of [6] have examined various factors such as temperature, aging, wind, pole movement and icing which effect the conductor sag and they have quoted some possible solutions. The authors of [7] have proposed a method to calculate the jump height of a line considering various factors such as energy conservation, stress sag relation, geometrical relations of sag and dynamic relation of clamps of a multispan transmission line following ice shedding. The authors of [8] have analyzed the jump heights due to vertical loading for a seven span transmission line system after ice shedding. The authors of [9] have simulated for unzipping effect considering three tests after ice shedding. The authors of [10] have considered five span system to analyze its dynamic behavior and to investigate on finding the jump height. They were the first to propose a theoretical method to find the jump height; however the calculations neglect the tension variations and vertical displacement [7].

With the increase in the weight on the conductor due to icing and wind pressure the horizontal tension of the line increases which results in conductor sagging and if the conductors are too elongated between supports, the stress on the conducts will reach an unsafe value and in some cases the conductors may even break. The sag should always be minimum to reduce the material usage and to avoid extra height of pole structure to maintain sufficient ground level clearance [6]. Most of the papers related to iced transmission lines concentrate on the dynamic characteristics of conductor lines after ice shedding and the methods to calculate jump height are rarely discussed which is also the opinion of authors in [7].The horizontal tension in the conductors determine the lowest point of sag in overhead lines [11]. According to the authors of [12], finding the span length due to elongation and lowest point of sag requires more resorting iterative techniques. This paper proposes a simple, improved calculation using algebraic method and an iterative approach to find the horizontal tension and hence the lowest point of sag considering levelled and unlevelled spans and the results are compared with Newton Raphson method. 


\section{NEWTON RAPHSON METHOD}

The maximum permissible tension $\mathrm{T}_{\max }$, Horizontal Tension $\mathrm{H}$ and the resultant weight on the conductor $\mathrm{w}_{\text {rcond }}$ are related by,

$$
T_{\text {max }}=H * \cosh \left[\frac{\left(w_{\text {rcond }} * x_{b}\right)}{H}\right]
$$

where, $x_{b}$ is the horizontal distance from the low point of sag to the right side support as depicted in figure1.

Considering the first two terms in cosh series and substituting in equation (1) we obtain,

$$
H^{2}-H T_{\max }+\frac{\left(w_{\text {rcond }}^{2} * x_{b}^{2}\right)}{2}=0
$$

Initially $\mathrm{H}$ is assumed to be equal to $\mathrm{T}_{\max }$ and the value of $\mathrm{H}$ is obtained solving equation (2).

An error function is defined by,

$$
\Delta T=T_{\max }-H * \cosh \left(\left(w_{\text {rcond }} * x_{b}\right) / H\right)
$$

Since the value of $\mathrm{H}$ is obtained using iteration method, the adjustment to the horizontal tension after $\mathrm{n}^{\text {th }}$ iteration is defined by ,

$$
\Delta H_{n}=-\frac{\Delta T_{n}}{\Delta T_{n}^{\prime}}
$$

Where,

$\Delta T_{\mathrm{n}}=$ The value of error function after $\mathrm{n}^{\text {th }}$ iteration

$$
\Delta T_{n}^{\prime}=\frac{\Delta T_{n}}{\Delta H_{n}}
$$

The value of $\mathrm{H}$ for $(\mathrm{n}+1)^{\text {th }}$ iteration is given by,

$$
H_{n+1}=H_{n}+\Delta H_{n}
$$

The iteration is continued until $\Delta \mathrm{T}$ becomes almost equal to zero.

\section{PROPOSED IMPROVED ALGEBRAIC METHOD}

Consider Fig. 1 where a conductor is tied between tower A and tower B forming an unlevelled span catenary. The nomenclature related to Fig. 1 is as follows,

$x_{a}$ is the horizontal distance from support A to the lowest point $\mathrm{O}$.

$x_{b}$ is the horizontal distance from point $\mathrm{O}$ to support $\mathrm{B}$.

$d_{a}$ is the vertical sag from support A to the lowest point.

$d_{b}$ is the vertical sag from support B to the lowest point.

$\mathrm{T}_{\max }$ be the allowable tension in the conductor.

$\mathrm{H}$ be the tension in the conductor at $\mathrm{O}$, i.e., the horizontal tension in the conductor.

$\mathrm{D}$ be the clearance from ground to the lowest point of sag.

$l$ be the span, i.e. the sum of $x_{a}$ and $x_{b}$

$\mathrm{w}_{\text {cond }}$ be the weight of the conductor.

$\mathrm{w}_{\text {ice }}$ be the weight of ice coating on the conductor.
$F_{\text {wind }}$ be the force of wind acting perpendicularly to the conductor.

$\mathrm{w}_{\mathrm{rcond}}$ be the resultant weight of the conductor given by,

$$
w_{\text {rcond }}=\sqrt{\left.\left(w_{\text {cond }}+w_{\text {ice }}\right)^{2}+\left(F_{\text {wind }}\right)^{2}\right]}
$$

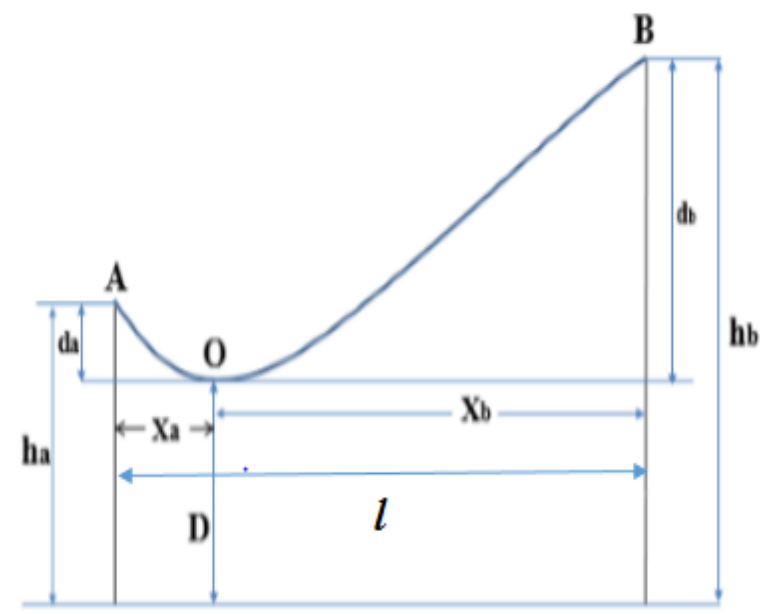

Fig.1: Unlevelled span conductor between tower A and tower B

From the literature as in equation (1) we have,

$$
\begin{array}{r}
T_{\max }=H * \cosh \left[\frac{\left(w_{\text {rcond }^{*}} x_{b}\right)}{H}\right] \\
x_{a}=\frac{l}{2}-\left(\frac{h H}{w_{\text {rcond }} * l}\right) \\
x_{b}=\frac{l}{2}+\left(\frac{h H}{w_{\text {rcond }} * l}\right)
\end{array}
$$
and,

$$
\begin{aligned}
& d_{a}=\left(\frac{H}{W}\right)\left[\cosh \left(w_{\text {rcond }} * \frac{x_{a}}{H}\right)-1\right] \\
& d_{b}=\left(\frac{H}{W}\right)\left[\cosh \left(w_{\text {rcond }} * \frac{x_{b}}{H}\right)+1\right]
\end{aligned}
$$

We Know that,

$$
\cosh (x)=1+\frac{x^{2}}{2 !}+\frac{x^{4}}{4 !}+\cdots
$$

Considering first three terms, we get,

$$
\cosh (x)=1+\frac{x^{2}}{2 !}+\frac{x^{4}}{4 !}
$$

Taking

$$
x=\frac{w_{\text {rcond }} * x_{b}}{H}
$$

and, substituting equation (13) in equation (1) we get,

$$
H^{4}-T_{\max } H^{3}+\left[\frac{w_{\text {rcond }}^{2} * x_{b}^{2}}{2}\right] * H^{2}+\left[\frac{w_{r \text { rond }}^{2} * x_{b}^{4}}{24}\right]=0
$$

This is of the form,

$$
a x^{4}+b x^{3}+c x^{2}+d x+e=0
$$


By comparing equations (15) and (16), we get

$\mathrm{a}=1$

$\mathrm{b}=-\mathrm{T}_{\max }$

$\mathrm{c}=\frac{\mathrm{w}_{\mathrm{rcond}}^{2} \cdot \mathrm{X}_{\mathrm{b}}^{2}}{2}$

$\mathrm{d}=0$

$\mathrm{e}=\frac{\mathrm{w}_{\text {rconc }}^{4} \cdot \mathrm{X}_{\mathrm{b}}^{4}}{24}$

The roots obtained after the first iteration are,

$\mathrm{x}_{1}=-\frac{b}{4 a}-\frac{p_{4}}{2}-\frac{\sqrt{p_{5}-p_{6}}}{2}$

$\mathrm{X}_{2}=-\frac{b}{4 a}-\frac{p_{4}}{2}+\frac{\sqrt{p_{5}-p_{6}}}{2}$

$\mathrm{X}_{3}=-\frac{b}{4 a}+\frac{p_{4}}{2}-\frac{\sqrt{p_{5}+p_{6}}}{2}$

$\mathrm{x}_{4}=-\frac{b}{4 a}+\frac{p_{4}}{2}+\frac{\sqrt{p_{5}+p_{6}}}{2}$

Where,

$$
\begin{aligned}
& P_{1}=2 c^{3}-9 b c d+27 a d^{2}+27 b^{2} e-72 a c e \\
& P_{2}=P_{1}+\sqrt{\left(-4\left(c^{2}-3 b d+12 a e\right)^{3}+P_{1}^{2}\right)} \\
& P_{3}=\left(\frac{c^{2}-3 b d+2 a e}{3 a q}\right)+\frac{3 a}{q}
\end{aligned}
$$

where,

$$
\begin{aligned}
& q=\left(\frac{p_{2}}{2}\right)^{\frac{1}{3}} \\
& P_{4}=\left(\frac{b^{2}}{4 a^{2}}-\frac{2 c}{3 a}+P_{3}\right) \\
& P_{5}=\left(\frac{b^{2}}{2 a^{2}}-\frac{4 c}{3 a}-P_{3}\right) \\
& P_{6}=\frac{-\frac{b^{3}}{a^{3}}+\frac{4 b c}{a^{2}}-\frac{8 d}{a}}{4 P_{4}}
\end{aligned}
$$

Out of the four roots we choose the one which is closer to $\mathrm{T}_{\max }$, we continue with the iteration to arrive at the convergence point .

For the case of levelled span, i.e., for conductors at equal height as shown in Fig.2,

$$
h=h_{b}-h_{a}=0
$$

therefore,

$$
h * \frac{H}{w_{\text {rcond }} * l}=0
$$

Hence,

$$
x_{a}=x_{b}=\frac{l}{2}
$$

In this case,

$$
d_{a}=d_{b}=d(s a y)
$$

Where,

$$
d=\left(w_{\text {rcond }} * l\right) /\left(8 * T_{\max }\right)
$$

and,

$$
\begin{gathered}
h_{a}=h_{b} \\
D=h_{a}-d_{a}=h_{b}-d_{b}
\end{gathered}
$$

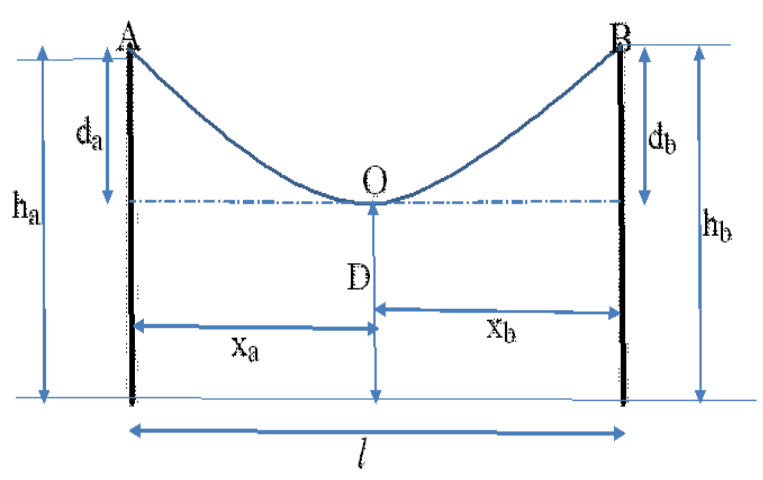

Fig.2. Conductors at equal height, levelled span

The above algebraic procedure for unlevelled span is programmed to arrive at the convergence point as shown in the Flow chart of Fig.3

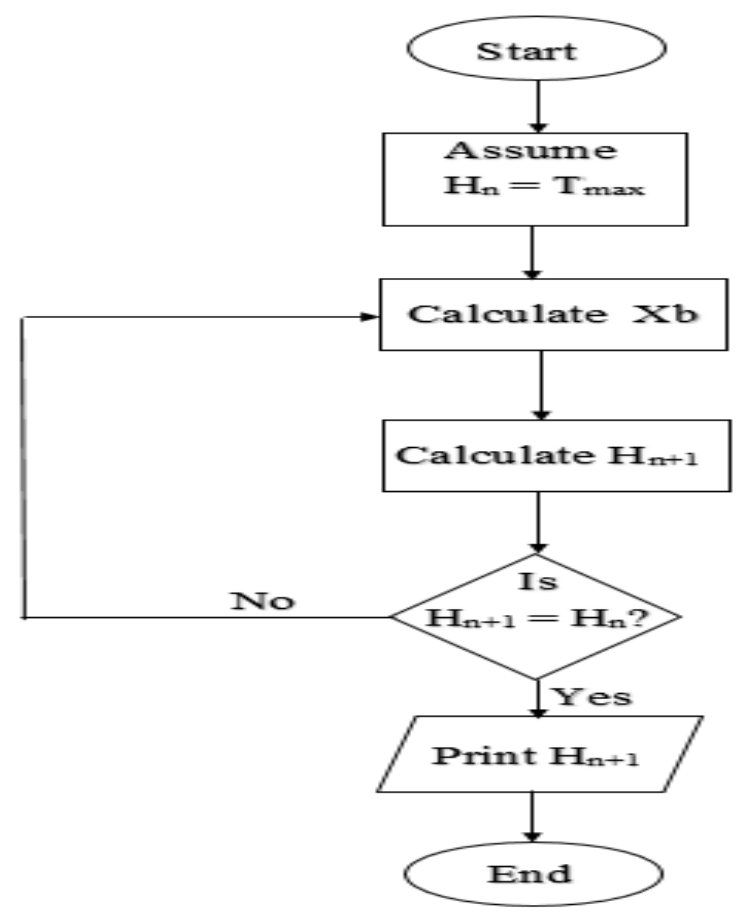

Fig.3. Flow chart for the computation of $\mathbf{H}$ 


\section{RESULTS AND DISCUSSION}

The proposed method is applied for an unlevelled span with parameter values as indicated in Table1 taken from [11] for comparison purpose and the results are given in Table 2. It is very interesting to observe that the values of $\mathrm{H}$ and $\mathrm{D}$ obtained from the proposed method are in error only by $0.0119 \%$ and $0.1596 \%$ respectively with respect to NR method. It should be noted that the proposed method involves less computation, reduced complexity, yet gives results very close to NR method in less number of iterations. The output of each iteration is shown in Table 3.

Table1. Parameter Values under Consideration

\begin{tabular}{|c|c|c|}
\hline SL.NO & PARAMETERS & VALUES \\
\hline 1 & $\mathrm{w}_{\text {rcond }}$ & $8.66 \mathrm{~N} / \mathrm{m}$ \\
\hline 2 & $\mathrm{~T}_{\max }$ & $19000 \mathrm{~N}$ \\
\hline 3 & $\mathrm{~h}_{\mathrm{a}}$ & $45.72 \mathrm{~m}$ \\
\hline 4 & $\mathrm{~h}_{\mathrm{b}}$ & $335.28 \mathrm{~m}$ \\
\hline 5 & $\boldsymbol{l}$ & $335.28 \mathrm{~m}$ \\
\hline
\end{tabular}

Table.2 RESULTS

\begin{tabular}{|c|c|c|c|}
\hline $\begin{array}{c}\text { PARAMET } \\
\text { ORS/METH } \\
\text { OD }\end{array}$ & $\begin{array}{c}\text { NEWTON } \\
\text { RAPHSON } \\
\text { METHOD }\end{array}$ & $\begin{array}{c}\text { PROPOSED } \\
\text { METHOD }\end{array}$ & $\begin{array}{c}\text { *ERROR } \\
(\%)\end{array}$ \\
\hline $\mathrm{d}_{\mathrm{a}}$ & $3.5641 \mathrm{~m}$ & $3.6313 \mathrm{~m}$ & -1.8505 \\
\hline
\end{tabular}

\begin{tabular}{|c|c|c|c|}
\hline $\mathrm{d}_{\mathrm{b}}$ & $49.2841 \mathrm{~m}$ & $49.54005 \mathrm{~m}$ & -0.5166 \\
\hline$x_{a}$ & $-123.627 \mathrm{~m}$ & $-124.7854 \mathrm{~m}$ & -0.9283 \\
\hline$x_{b}$ & $458.907 \mathrm{~m}$ & $460.06574 \mathrm{~m}$ & -0.2518 \\
\hline $\mathrm{H}$ & $18573.2000 \mathrm{~N}$ & $18570.98 \mathrm{~N}$ & 0.0119 \\
\hline $\mathrm{D}$ & $42.1559 \mathrm{~m}$ & $42.0887 \mathrm{~m}$ & 0.1596 \\
\hline
\end{tabular}

$\%$ error $=$

$\left[\frac{\text { value obtained from NR method-value obtained from proposed method }}{\text { value obtained from proposed method }}\right]$ * 100

\section{CONCLUSION}

An improved algebraic calculation method for finding the jump height of transmission line conductors due to external loading like ice and wind, stung at two different pole tower levels is proposed in this paper. The method is simple, accurate, easy to program when compared with other methods. The various parameters like Horizontal tension, displacement of the conductor, lowest point of sag and ground clearance are effectively calculated and compared with Newton Raphson method and we see that the proposed method is able to arrive at the convergence point within 6 iterations as compared with NR method which takes 7 iterations for finding the exact convergence point for horizontal tension. The proposed method has an error on application of only $0.0119 \%$ for horizontal tension as seen with NR method.

Table 3. Iteration Output

\begin{tabular}{|c|c|c|c|c|c|c|}
\hline Parameter & Iteration 1 & Iteration 2 & Iteration 3 & Iteration 4 & Iteration 5 & Iteration 6 \\
\hline $\mathbf{a}$ & 1.000000 & 1.000000 & 1.000000 & 1.000000 & 1.000000 & 1.000000 \\
\hline b & -19000.000000 & -19000.000000 & -19000.000000 & -19000.000000 & -19000.000000 & -19000.000000 \\
\hline c & 8171596.391705 & 7929711.725846 & 7937016.701557 & 7936796.226167 & 7936802.880577 & 7936802.679733 \\
\hline d & 0.000000 & 0.000000 & 0.000000 & 0.000000 & 0.000000 & 0.000000 \\
\hline $\mathbf{e}$ & $\begin{array}{l}11129164598153 \\
.182000\end{array}$ & $\begin{array}{l}10480054675835 \\
646000\end{array}$ & $\begin{array}{l}10499372353464 . \\
697000\end{array}$ & $\begin{array}{l}1049878905594 \\
8.580000\end{array}$ & $\begin{array}{l}10498806660855 \\
635000\end{array}$ & $\begin{array}{l}10498806129502 . \\
646000\end{array}$ \\
\hline $\mathbf{p}_{1}$ & $\begin{array}{l}10301938486182 \\
1790000000.000 \\
000\end{array}$ & $\begin{array}{l}97162864178341 \\
406000000.00000 \\
0\end{array}$ & $\begin{array}{l}97337360705701 \\
758000000.00000 \\
0\end{array}$ & $\begin{array}{l}9733209196681 \\
6535000000.000 \\
000\end{array}$ & $\begin{array}{l}973322509864499 \\
33000000.000000\end{array}$ & $\begin{array}{l}97332246186904 \\
309000000.00000 \\
0\end{array}$ \\
\hline $\mathbf{p}_{2}$ & $\begin{array}{l}20588258246718 \\
9500000000.000 \\
000\end{array}$ & $\begin{array}{l}19418745229935 \\
1810000000.0000 \\
00\end{array}$ & $\begin{array}{l}19453592836807 \\
7240000000.0000 \\
00\end{array}$ & $\begin{array}{l}1945254065151 \\
12200000000.00 \\
0000\end{array}$ & $\begin{array}{l}194525724082809 \\
000000000.00000 \\
0\end{array}$ & $\begin{array}{l}19452571449795 \\
0740000000.0000 \\
00\end{array}$ \\
\hline $\mathbf{p}_{3}$ & $\begin{array}{l}17046980.40217 \\
2\end{array}$ & 16688700.653826 & 16699562.520740 & $\begin{array}{l}16699234.73146 \\
6\end{array}$ & 16699244.624870 & 16699244.326267 \\
\hline $\mathbf{p}_{4}$ & 10092.038916 & 10082.272867 & 10082.570012 & 10082.561046 & 10082.561317 & 10082.561309 \\
\hline $\mathbf{p}_{5}$ & $\begin{array}{l}152557557.7422 \\
22\end{array}$ & $\begin{array}{l}153238350.37838 \\
0\end{array}$ & $\begin{array}{l}153217748.54385 \\
1\end{array}$ & $\begin{array}{l}153218370.3003 \\
12\end{array}$ & $\begin{array}{l}153218351.53436 \\
1\end{array}$ & $\begin{array}{l}153218352.10075 \\
6\end{array}$ \\
\hline $\mathbf{p}_{6}$ & $\begin{array}{l}154526719.6843 \\
70\end{array}$ & $\begin{array}{l}155132230.38107 \\
3\end{array}$ & $\begin{array}{l}155113892.66444 \\
2\end{array}$ & $\begin{array}{l}155114446.0776 \\
96\end{array}$ & $\begin{array}{l}155114429.37447 \\
9\end{array}$ & $\begin{array}{l}155114429.87861 \\
6\end{array}$ \\
\hline
\end{tabular}




\begin{tabular}{|l|l|l|l|l|l|l|}
\hline $\mathbf{x}_{\mathbf{1}}$ & -997.653611 & -979.227998 & -979.787751 & -979.770860 & -979.771370 & -979.771355 \\
\hline $\mathbf{x}_{\mathbf{2}}$ & 405.614696 & 396.955131 & 397.217739 & 397.209814 & 397.210053 & 397.210046 \\
\hline $\mathbf{x}_{\mathbf{3}}$ & 1034.109315 & 1010.894684 & 1011.597637 & 1011.576422 & 1011.577063 & 1011.577043 \\
\hline $\mathbf{x}_{\mathbf{4}}$ & 18557.929601 & 18571.378184 & 18570.972375 & 18570.984624 & 18570.984254 & 18570.984265 \\
\hline $\mathbf{H}$ & 18557.929601 & 18571.378184 & 18570.972375 & 18570.984624 & 18570.984254 & 18570.984265 \\
\hline
\end{tabular}

\section{ACKNOWLEDGMENTS}

The authors would like to thank JSS Research Foundation, JSS Mahavidyapeetha, Mysuru and the Management of Vidyavardhaka College of Engineering, Mysuru, Karnataka, India for supporting this research work.

\section{REFERENCES}

[1] V.H.Greisser, "Effects of Ice Loading on Transmission Lines", paper presented at the $285^{\text {th }}$ meeting of American Institute of Electrical Engineers, Sep 9, 1913

[2] Kai-qin Li, Liang Du, Wei-heng Han, "Icing Analysis of Transmission Lines Considering the Current Heat", Power and Energy Engineering Conference, 2011 Asiapacific, DOI: 10.1109/APPEEC.2011.5748707.

[3] Alen HATIBOVICS, EDF DÉMÁSZ Hálózat, "Determination Of The Lowest Point Of The Conductor In Inclined Spans Based On A Known Maximal Sag Of The Parabola", $22^{\text {nd }}$ International Conference on Electricity Distribution, CIRED, June 2013

[4] Yoseph Mekonnen Abebe, P. Mallikarjuna Rao," Overhead Transmission Line Sag, Tension and Length Calculation using Affine Arithmetic", Power, Communication and Information Technology Conference, IEEE, 2015

[5] Bo Yan, Kequan Chen, Yueming Guo, Ming Liang, and Qi Yuan, "Numerical Simulation Study on Jump Height of Iced Transmission Lines After Ice Shedding", IEEE Transactions On Power Delivery, VOL. 28, NO.1, JANUARY 2013
[6] Oluwajobi F. I., Ale O. S. and Ariyanninuola A., "Effect of Sag on Transmission Line", Journal of Emerging Trends in Engineering and Applied Sciences (JETEAS) 3 (4): 627-630, (ISSN: 2141-7016), 2012

[7] ChuanWu, Bo Yan,, Liang Zhang, Bo Zhang, Qing Li, "A method to calculate jump height of iced transmission lines after ice-shedding “Journal of Cold Regions Science and Technology, 125 (2016) 40-47, Elsevier

[8] Yang, F.L., Yang, J.B., Zhang, H.J., "Analyzing loads from ice shedding conductors for UHV transmission towers in heavy icing areas". J. Cold Reg. Eng. 28 (04014004-1-18), 2014

[9] Van Dyke, P., Havard, D., Laneville, A.," Effect of ice and snow on dynamics of transmission line conductors", Atmospheric Icing of Power Networks. Springer, pp. 219-222, 2008

[10] Morgan, V.T., Swift, D.A., "Jump height of overheadline conductors after the sudden release of ice loads" Proc. Inst.Elect. Eng. 111 (10), 1736-1746, 1964

[11] Japhet D. Sakala, "Improved calculation of sag for a conductor supported at unequal heights", International Journal of Electrical Engineering Education, DOI:10.7227/IJEEE.45.4.6, Oct.2008

[12] F. Kiessling, P. Nefzger, J. F. Nolasco and U. Kaintyzyk, "Overhead Power Lines Planning, Designing and Construction" (Springer, Berlin, 2003), pp. 539-570. 